$\mathbb{T}$ periodica polytechnica

Mechanical Engineering

$53 / 1(2009) 4148$

doi: 10.3311/pp.me.2009-1.06

web: http://www.pp.bme.hu/me

(c) Periodica Polytechnica 2009

RESEARCH ARTICLE

\section{Thermal comfort of closed spaces. Fundamentals of static and dynamic heat balance of human body}

\author{
Imrich Bartal / László Bánhidi
}

Received 2010-01-18

\begin{abstract}
The growing mechanization and industrialization of society has resulted in most people spending greater part of their lives - 85-90\% - in artificial climate. In this climate, thermal comfort can be basically predicted by the environment parameters such as temperature, humidity, air velocity and by the personal parameters as activity and clothing resistance. This paper intends to present the basic equations of the classical comfort theory, the equations of the human body's static heat balance, and the so called comfort equation as well as its sensitivity depending on the thermic parameters of the microclimate. The PMV expression describs the thermal comfort of the human body and its sensitivity. The concept of dynamic thermal sensation and the possibilities of its research will be introduced.
\end{abstract}

\section{Keywords}

Thermal comfort $\cdot P M V \cdot$ static heat balance $\cdot$ dynamic heat balance $\cdot$ thermal sensation

\section{Imrich Bartal}

Department of Building Service and Process Engineering, BME, H-1111 Budapest, Bertalan Lajos utca 4-6, Hungary

e-mail: bartalimi@gmail.com

\section{László Bánhidi}

Department of Building Service and Process Engineering, BME, H-1111 Budapest, Bertalan Lajos utca 4-6, Hungary

\section{Introduction}

The way we design, construct, and operate buildings has profound implications for the quality of both the natural and built environments. All too often today's buildings require massive resource inputs, create bleak or potentially unhealthy indoor environments, pollute both their local and global environments through increased greenhouse emissions, as well as contributing to the destruction of natural habitats.

Thermal comfort is generally associated with a neutral or near neutral whole body thermal sensation. Thermal sensation depends on body temperature, which in turn depends on thermal balance and the effects of environmental factors (air temperature, relative humidity, air velocity, and mean radiant temperature), as well as personal factors (metabolism and clothing). Skin and internal temperatures, skin moisture and physiological processes all contribute to human satisfaction. Comfort seems to occur when body temperatures are maintained with the minimum physiological regulatory effort.

According to the research approach used in the last two decades (comfort theory, thermal-comfort - research) the analysis of the joint impact of microclimate parameters can be based on the energy balance of an active or sedentary human who has a mechanical or thermal connection with his/her environment.

\section{Classifying and measuring thermal comfort}

Human response to thermal environment and the satisfaction with thermal comfort are expressed by subjective thermal sensation. Thermal comfort is linked to the heat balance of the human body: the time and the adaptation reactions required to achieve this balance and whether it is agreeable for the given person and what skin temperature and perspiration are measured.

ASHRAE expresses subjective thermal sensation using the thermal sensation scale:

$$
\begin{gathered}
+3 \text { (hot), }+2 \text { (warm), +1 (slightly warm), } \\
0 \text { (neutral), }-1 \text { (slightly cool), }-2 \text { (cool), }-3 \text { (cold) }
\end{gathered}
$$

The agreeable thermal sensation falls between -1 and +1 on the scale. In an experiment conducted with several thousand live subjects the test persons had to declare (after a relaxation 
interval) how they felt in the examined microclimate and what value they voted for on the scale.

P. O. Fanger based the investigation of thermal sensation on writing up and calculating the energy balance of the human body and established a mathematical connection between the solutions of the energy balance and the thermal sensation scale [1].

If the thermal impacts of the environment change, a human conducting a certain activity in a given thermal environment will try to set off the balance of heat production and heat loss by increasing or reducing heat loss in a transient process. Fanger examined only the static heat balance of the human body, after the heat equilibrium caused by the transient process set in.

In our papers we demonstrate the research on the heat balance of human body.

\section{Static heat balance of the human body}

Using the static heat balance of the human body, we estimate the body like a thermodynamic system, in which the result of oxygen uptake and metabolism is heat generation. This heat utilizes the human body for brawn work. With brawn work or with displacement of human body we can generate mechanical work.

By Fanger, the static heat balance of human body is calculated with the heat evolved from metabolism, with the physical muscle work and the heat dispersion of the body. In static condition the equation balance must be equal to zero.

Heat balance equation of the human body.

$$
H-\cdot Q_{L}-\cdot Q_{r e}-\cdot Q_{d}-\cdot Q_{s w}=\cdot Q_{K}=R+C .
$$

This equation is solved in detail by book [1] listed in the References.

After displacement of expression meant above to the formula (1) we get this heat balance equation:

$$
\begin{aligned}
& \frac{M}{A_{D u}}(1-\eta)-3,05.10^{-3}\left[5733-6,99 \cdot \frac{M}{A_{D u}}(1-\eta)-p_{a}\right]- \\
& \frac{E_{s w}}{A_{D u}}-1,7.10^{-5} \frac{M}{A_{D u}}\left(5867-p_{a}\right)- \\
& 0,0014 \frac{M}{A_{D u}}\left(34-t_{a}\right)=\frac{t_{s}-t_{c l}}{0,18 I_{c l}}=3,96.10^{-8} \\
& f_{c l}\left[\left(t_{c l}+273\right)^{4}-\left(t_{m r t}+273\right)^{4}\right]+f_{c l} h_{c}\left(t_{c l}-t_{a}\right) .
\end{aligned}
$$

In Eq. (2) vapour and waterproofability of clothing are not included.

The most important factors, which influence the heat balance of human body on thermal interaction with environment and on body comfort:

activity level, inertial heat production in human body, clothing thermal resistance, clothing heat loss, ambient air temperature, operative temperature, relative air velocity (drought), partial water vapour pressure in inspired air (ambient air), relative humidity.

The energy released by the oxidation processes in the human body per unit time

$$
M=W+H \quad[W] .
$$

Mechanical power:

$$
W=M \cdot \eta \quad[W],
$$

external mechanical effciency:

$$
\eta=\frac{W}{M}
$$

Heat loss of the human body:

$$
H=M(1-\eta) \quad[W]
$$

\section{Static thermal comfort equation}

Fanger's experiments have shown that the thermal sensation (thermal comfort) of an active person is deemed agreeable if the following criteria are met:

- The static energy balance describing the thermal and mechanical connection between the human and his environment is zero, and the resultant of the heat produced and lost as well as the performed work is zero,

- Human skin temperature remains within a narrow range,

- Perspiration remains within a given range.

This was expressed by Fanger by the following inequalities:

$$
a<t_{s}<b, \quad c<E_{s w}<d .
$$

According to the experiments skin temperature in the state of agreeable thermal comfort only depends on metabolism and heat loss through perspiration is similarly linked to metabolic heat in a defined statistical connection.

Fanger found that skin temperature in the state of agreeable thermal comfort has the following regressive relationship with metabolic heat.

$$
\bar{t}_{s}=35,7-0,032 \frac{M}{A_{D u}} \quad\left[{ }^{o} C\right] .
$$

Fanger also discovered that the regressive relationship between heat loss by perspiration and metabolic heat in the state of agreeable thermal comfort is as follows:

$$
Q_{s w}=0,42\left[\frac{M}{A_{D u}}(1-\eta)-58,15\right] \quad[\mathrm{W}] .
$$

The comfort equation describing the heat balance of the human body in the state of thermal comfort is the following:

$$
\begin{aligned}
& \frac{M}{A_{D u}}(1-\eta)-3,05.10^{-3}\left[5733-6,99 \cdot \frac{M}{A_{D u}}(1-\eta)-p_{a}\right]- \\
& 0,42\left[\frac{M}{A_{D u}}(1-\eta)-58,15\right]-1,7.10^{-5} \frac{M}{A_{D u}}\left(5867-p_{a}\right) \\
& -0,0014 \frac{M}{A_{D u}}\left(34-t_{a}\right)=3,96.10^{-8} f_{c l} \\
& {\left[\left(t_{c l}+273\right)^{4}-\left(t_{m r t}+273\right)^{4}\right]+f_{c l} h_{c}\left(t_{c l}-t_{a}\right) .}
\end{aligned}
$$

This equation is discussed in detail by books [1] and [2] listed in the References. 


\section{Co-dependency of comfort parameters}

Fanger processed his findings about the dependence of the solution of comfort equation and the factors influencing the thermal comfort (with using the pertaining derivatives) in diagrams [1]. Using the comfort equation derivatives describing the codependency of the activity level, the clothing and the climate parameters are obtained. Derivatives express the change that is produced by the unit change on the variable in the numerator while the value of comfort equation remains zero, which we are present detail in [11] listed in the References.

\section{PMV the complex measurement value of thermal comfort}

\subsection{Theoretical and empirical fundamentals of PMV}

Fanger introduced the term thermal load of the human body which is calculated by differing from 0 in the comfort equation as follows [1,2]:

$$
\begin{aligned}
& L=\frac{M}{A_{D u}}(1-\eta)- \\
& 3,05.10^{-3}\left[5733-6,99 \frac{M}{A_{D u}}(1-\eta)-p_{a}\right]- \\
& 0,42\left[\frac{M}{A_{D u}}(1-\eta)-58,15\right]-1,7.10^{-5} \\
& \frac{M}{A_{D u}}\left(5867-p_{a}\right)-0,0014 \frac{M}{A_{D u}}\left(34-t_{a}\right)-3,96.10^{-8} f_{c l} \\
& {\left[\left(t_{c l}+273\right)^{4}-\left(t_{m r t}+273\right)^{4}\right]+f_{c l} h_{c}\left(t_{c l}-t_{a}\right) .}
\end{aligned}
$$

Conducting masses of experiments and using the live subjects' votes Fanger looked for a mathematically defined function between the ASHRAE scale [1] and thermal load $L$ on an empirical basis.

In research on different activity level they changed the external temperature and the speed of environ air of test person but clothing and his heat-proof capability will be constant. The mean radiation temperature of surface was equal to air temperature. During the three hour experiment the environment variables were constant. The attendees range their own thermal sensation on ASHRAE scale about environment.

With observance of attendance feelings they generate a regression function based on expected heat feeling $(Y)$ and on external air temperature $(t)$.

Tab. 1.

\begin{tabular}{lllll}
\hline Activity level & $\begin{array}{l}\mathrm{M} / \mathrm{A}_{D u} \\
\mathrm{~W} / \mathrm{m} 2\end{array}$ & $\begin{array}{l}\mathrm{I}_{c l} \\
\text { clo }\end{array}$ & $\begin{array}{l}\mathrm{v} \\
\mathrm{m} / \mathrm{s}\end{array}$ & $\begin{array}{l}\mathrm{Y} \text { thermal sensation } \\
(\mathrm{eh}=50 \%)\end{array}$ \\
\hline Sedentary & 58,15 & 0,6 & 0,1 & $\mathrm{Y}=-4,471+0,331 \mathrm{t}$ \\
Low & 93,04 & 0,6 & 0,2 & $\mathrm{Y}=-3,643+0,175 \mathrm{t}$ \\
Medium & 123,28 & 0,6 & 0,25 & $\mathrm{Y}=-3,356+0,174 \mathrm{t}$ \\
High & 157 & 0,6 & 0,32 & $\mathrm{Y}=-4,158+0,265 \mathrm{t}$ \\
\hline
\end{tabular}

We need to define that by using regression on measurable points we get the thermal sensation of expectable mathematical equation. Another interesting question would be the investigation of expectable result on measured result, the dispersion.

The Fig. 1 shows the relation of the expectable thermal sensation on external temperature in four activity levels.

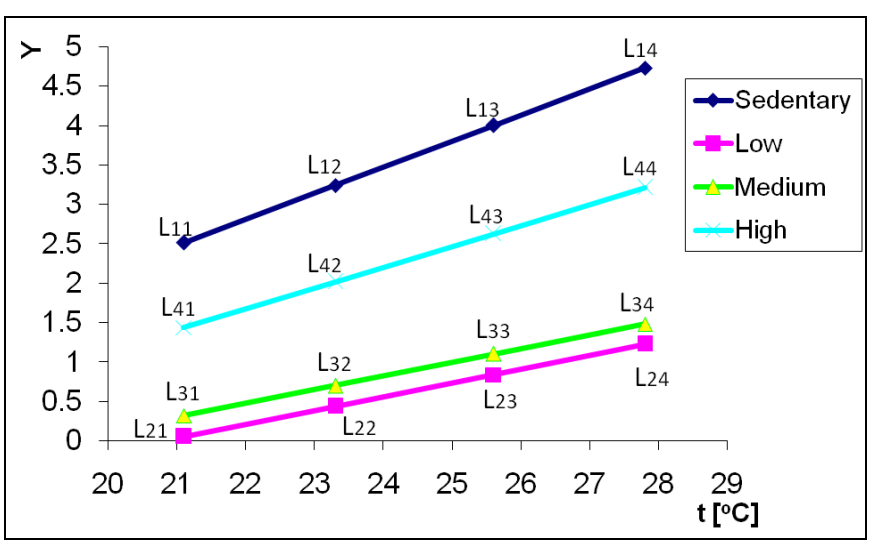

Fig. 1.

We assign on the regression chart 4-4 points and for this we get the values, which specify the person catch heat load. The result is numerated in table below (Tab.2):

Tab. 2.

\begin{tabular}{lllll}
\hline $\begin{array}{l}\text { Activity } \\
\text { level }\end{array}$ & & \multicolumn{2}{c}{ Value of thermal load } \\
\hline Sedentary & $\mathrm{L} 11=-22,94$ & $\mathrm{~L} 12=-11,25$ & $\mathrm{~L} 13=0,69$ & $\mathrm{~L} 14=12,54$ \\
Low & $\mathrm{L} 21=-6,02$ & $\mathrm{~L} 22=6,75$ & $\mathrm{~L} 23=20,04$ & $\mathrm{~L} 24=33,23$ \\
Medium & $\mathrm{L} 31=2,87$ & $\mathrm{~L} 32=16,24$ & $\mathrm{~L} 33=30,13$ & $\mathrm{~L} 34=43,93$ \\
High & $\mathrm{L} 41=19,39$ & $\mathrm{~L} 42=33,61$ & $\mathrm{~L} 43=48,36$ & $\mathrm{~L} 44=63,01$ \\
\hline
\end{tabular}

Reusing the table values on the dependency of catch heat load $(L)$ we get the $Y$ value of thermal sensation diagram on separate activity levels, which is shown in Fig. 2. The functional connec-

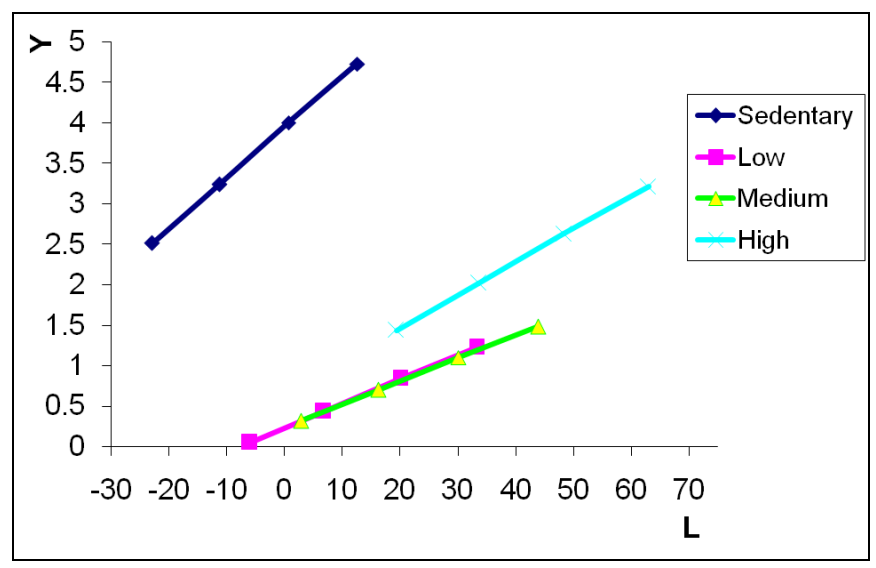

Fig. 2.

tion between the thermal sensation and the thermal load might vary with the derivatives $\partial Y / \partial L$ from activity level in Fig. 3 .

Calculation for $\partial \mathrm{Y} / \partial \mathrm{L}$ is demonstrated below:

$$
\begin{array}{ll}
\frac{\partial Y_{1}}{\partial L_{1}}=\frac{Y_{14}-Y_{11}}{L_{14}-L_{11}}, & \frac{\partial Y_{2}}{\partial L_{2}}=\frac{Y_{24}-Y_{21}}{L_{24}-L_{21}}, \\
\frac{\partial Y_{3}}{\partial L_{3}}=\frac{Y_{34}-Y_{31}}{L_{34}-L_{31}}, & \frac{\partial Y_{4}}{\partial L_{4}}=\frac{Y_{44}-Y_{41}}{L_{44}-L_{41}}
\end{array}
$$

Solved value $\left(\partial Y_{n} / \partial L_{n}\right)$ as a function of $M / A_{D u}$ is demonstrated in Fig. 3 . 


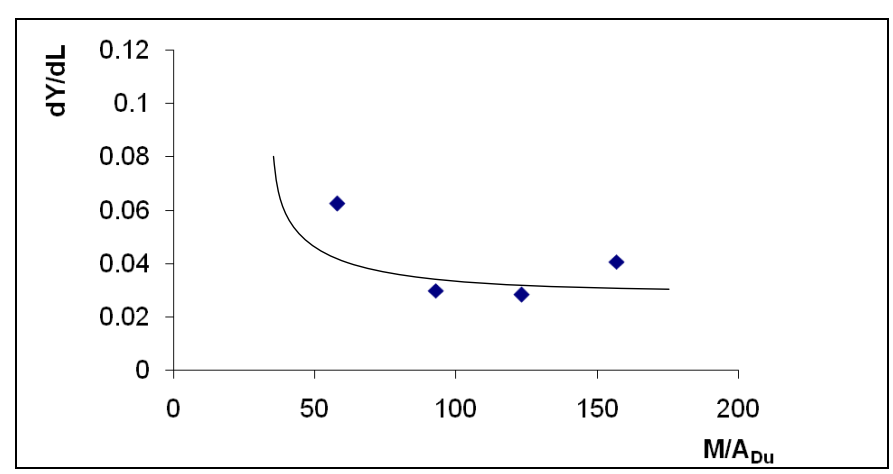

Fig. 3.

For the points in Fig. 3, Fanger calculated a regression chart.

$$
\frac{\partial Y}{\partial L}=\left(0,303 \cdot e^{-0,036 \frac{M}{A_{D u}}}+0,028\right)
$$

This expression is in fact a differential equation which can be integrated to produce the dependence of the thermal comfort indicator $(Y)$ on the thermal load of the human body $(L)$.

The integrated of the differential equation:

$$
\begin{aligned}
& Y=P M V=\left(0,303 \cdot e^{-0,036 \frac{M}{A_{D u}}}+0,028\right) \cdot\left\{\frac{M}{A_{D u}}(1-\eta)-\right. \\
& -3,05 \cdot 10^{-3} \cdot\left[5733-6,99 \frac{M}{A_{D u}}(1-\eta)-p_{a}\right]--0,42 \\
& {\left[\frac{M}{A_{D u}}(1-\eta)-58,15\right]-1,7.10^{-5} \frac{M}{A_{D u}}\left(5867-p_{a}\right)-} \\
& -0,0014 \frac{M}{A_{D u}}\left(34-t_{a}\right)-3,96.10^{-8} f_{c l} \\
& \left.\left[\left(t_{c l}+273\right)^{4}-\left(t_{m r t}+273\right)^{4}\right]+f_{c l} h_{c}\left(t_{c l}-t_{a}\right)\right\} .
\end{aligned}
$$

Thermal comfort indicator $Y$ calculated with the above equation was called PMV, the predicted mean vote by Fanger [1, 6].

The physically reasonable solutions of the thermal comfort indicator fall between -3 and +3 . PMV can be used in two ways:

- PMV is calculated for different activity levels, various environmental and clothing parameters to classify our environment and thermal sensation: between -1 and +1 thermal comfort is described as slightly cool, neutral and slightly warm.

- the inverse of the above: environmental microclimate parameters are defined for the activity level and clothing linked to a specified PMV or PMV range (practically $-1,+1$ range) to meet the criteria of the given PMV.

The above tasks can be carried out using mathematical operations on Eq. (13).

To perform the tasks the derivatives of the PMV function has been produced in function of the different microclimate parameters and $\mathrm{I}_{c l}$ characterizing the activity level and clothing. Derivatives also showed the sensitivity of PMV in function of the various factors and in case of slight changes provided us with answers about how to compensate the impact of a given factor by modifying the value of another factor.

\subsection{Sensitivity and derivatives of PMV}

The (PMV) thermal sensation indicator is expressed by its derivatives. Fanger produced these derivatives numerically and introduced them with help of diagrams. The following presented the explicit mathematical functions of the derivatives; of which we are present in detail [5] listed in the References.

\section{Dynamic heat balance of human body}

\subsection{Mathematical modelling}

Many people examined the dynamic heat balance in the past years some of them: B. W. Olesen, Muhsin Kilic, Omer Kaynakli, Mihaela Baritz, Luciana Cristea, Diana Cotoros and Ion Balcu.

Mihaela Baritz, Luciana Cristea, Diana Cotoros and Ion Balcu are presented the differential equation describe the dynamic heat balance of human body, can be calculated as follows [12]:

$$
k\left(\frac{\partial^{2} T}{\partial r^{2}}+\frac{\omega}{r} \frac{\partial T}{\partial r}\right)+q_{m}+\rho_{b l} w_{b l} c_{b l}\left(T_{a r t b l}-T\right)=\rho_{c} \frac{\partial T}{\partial t}
$$

TSENS and DISC values can be calculated by the following equations [8]:

$$
\mathrm{TSENS}= \begin{cases}0,4685\left(T_{b}-T_{b, c}\right) & T_{b}<T_{b, c} \\ 4,7 \eta_{e}\left(T_{b}-T_{b, c}\right) /\left(T_{b, h}-T_{b, c}\right) & T_{b, c} \leq T_{b} \leq T_{b, h} \\ 4,7 \eta_{e}+0,685\left(T_{b}-T_{b, h}\right) & T_{b, h}<T_{b}\end{cases}
$$

$$
\text { DISC }= \begin{cases}0,4685\left(T_{b}-T_{b, c}\right) & T_{b}<T_{b, c} \\ 4,7\left(Q_{e, r s w}-Q_{e, r s w, r e q}\right) & T_{b, c} \leq T_{b} . \\ \hline Q_{e, \text { max }}-Q_{e, r s w, r e q}-Q_{e, \text { dif }} & \end{cases}
$$

Scales of TSENS, \pm 5 intolerable hot/cold, \pm 4 very hot/cold, \pm 3 hot/cold, \pm 2 warm/cool, \pm 1 slightly warm/cool, 0 neutral.

Fort the DISC, 0 comfortable, \pm 1 slightly uncomfortable but acceptable, \pm 2 uncomfortable and unpleasant, \pm 3 very uncomfortable, \pm 4 limited tolerance, \pm 5 intolerable.

B. W. Olesen, Muhsin Kilic and Omer Kaynakli developed a mathematical model to describe the dynamic heat balance of the human body, taking into account the heat storage capacity of the human body and clothing as seen on Fig. 4

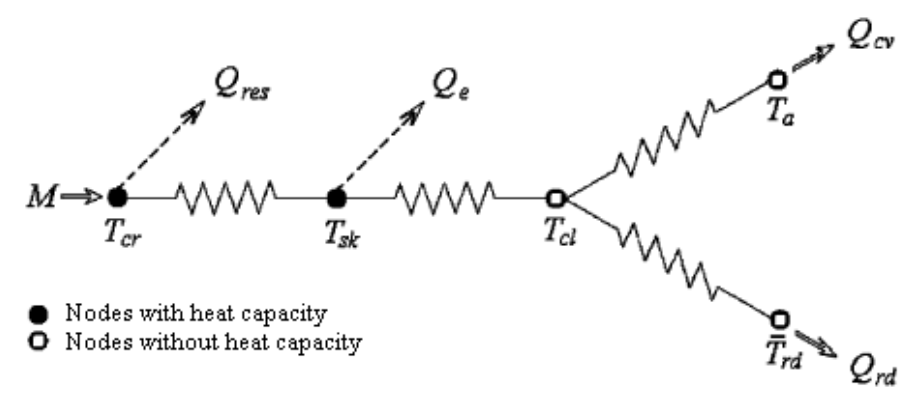

Fig. 4. 
Heat flows originating from the core of the human body are calculated with help of heat resistances defined for certain body parts. Heat leaving the body surface is conducted via clothes, then with radiation and convection. Theoretically, the dry and hidden heat generated by exhalation should be taken into account as well. The considered heat resistances are calculated with the following formulas:

The total thermal resistance $\left(\mathrm{R}_{t}\right)$ and the total evaporative resistance $\left(\mathrm{R}_{e, t}\right)$ for each segment can by calculated as follows [9]:

$$
\begin{aligned}
& R_{t}(i)=R_{a}(i) \frac{r(i, 0)}{r(i, n l)}+\sum_{j=1}^{n l}\left[R_{a l}(i, j) \frac{r(i, 0)}{r(i, j-1)}\right. \\
& \left.+R_{f}(i, j) \frac{r(i, 0)}{r(i, j)}\right], \\
& R_{e, t}(i)=R_{e, a}(i) \frac{r(i, 0)}{r(i, n l)}+\sum_{j=1}^{n l}\left[R_{e, a l}(i, j) \frac{r(i, 0)}{r(i, j-1)}\right. \\
& \left.+R_{e, f}(i, j) \frac{r(i, 0)}{r(i, j)}\right],
\end{aligned}
$$

where $\mathrm{R}_{a}$ and $\mathrm{R}_{e, a}$ are the thermal and evaporative resistances of the outer air layer, $\mathrm{R}_{a l}$ and $\mathrm{R}_{e, a l}$ are the thermal and evaporative resistances of the air layer between the clothing layers. Detailed information about these resistances may be found in McCullough et al. [9] and Kaynakli et al. [10].

The sensible heat losses (convective and radiative) for each segment are calculated as follows:

$$
Q_{s, s k}(i)=\frac{T_{s k}(i)-T_{0}(i)}{R_{t}(i)}
$$

where $\mathrm{T}_{s k}$ and $\mathrm{T}_{o}$ are the skin and operative temperatures.

Operative temperature:

$$
T_{0}(i)=\frac{h_{c v}(i) T_{a}+h_{r d} \bar{T}_{r d}}{h_{c v}(i)+h_{r d}}
$$

where $\mathrm{h}_{c v}$ and $\mathrm{h}_{r d}$ are convective and radiative heat transfer coefficients, $\mathrm{h}_{r d}$ is assumed $4,7 \mathrm{~W} / \mathrm{m}^{2} \mathrm{~K}[8]$. The convective heat transfer coefficients for entire body and of the body are given in de Dear et al. [12].

Evaporative heat loss from skin $\left(\mathrm{Q}_{e, s k}\right)$ depends on the difference between the water vapour pressure at the skin $\left(\mathrm{p}_{s k}\right)$ and in the ambient environment $\left(\mathrm{p}_{a}\right)$, and the amount of moisture on the skin (w):

$$
Q_{e, s k}(i)=\frac{w(i)\left(p_{s k}(i)-p_{a}\right)}{R_{e, t}(i)}
$$

Total skin wettedness (w) includes wettedness due to regulatory sweating $\left(\mathrm{w}_{r s w}\right)$ and to diffusion through the skin $\left(\mathrm{w}_{d i f}\right) . \mathrm{w}_{r s w}$ and $\mathrm{w}_{\text {dif }}$ are given by:

$$
\begin{gathered}
w_{r s w}=\frac{\dot{m}_{r s w} h_{f g}}{Q_{e, \max }} \\
w_{d i f}=0,06\left(1-w_{r s w}\right)
\end{gathered}
$$

where the $\mathrm{Q}_{e, \max }$ is the maximum evaporative potential, $\mathrm{m}_{r s w}$ is the rate of sweat production, $\mathrm{h}_{f g}$ the heat of vaporization of water.
The blood flow between the core and skin per unit of skin area can be expressed mathematically as:

$$
\dot{m}_{b 1}=\frac{\left[\frac{\left(6,3+200 W S I G_{c r}\right)}{1+0,5 C S I G_{s k}}\right]}{3600}
$$

where WSIG and CSIG are warm and cold signal from the body thermoregulatory control mechanism, respectively.

The heat exchange between the core and skin can be written as:

$$
Q_{c r, s k}=\left(K+c_{p, b l} \dot{m}_{b l}\right)\left(T_{c r}-T_{s k}\right)
$$

where $K$ is average thermal conductance, $\mathrm{c}_{p, b l}$ is specific heat of blood.

The rate of sweat production per unit of skin area is estimated by:

$$
\dot{m}_{r s w}=4,7 \times 10^{-5} W S I G_{b} \exp \left(\frac{W S I G_{s k}}{10,7}\right) .
$$

\subsection{Method of the research}

In his live subject experiments Fanger placed his subjects under various activities and thermal loads where the produced and lost heat was not in balance at the initial phase of the examined interval. This was expressed by the deviation from 0 in thermal load $L$ of the human body. Naturally if the human body was able to undergo an adaptation process the heat balance was achieved and the $L$ thermal load of the human body turned 0 . Through their votes live subjects were describing this adaptation process. Their votes obviously expressed what new core temperature was required to achieve the new $L=0$ heat balance and whether it was agreeable or disagreeable for them. This shows the weak point of Fanger's theory: the regressive straight lines of skin temperatures and perspiration values considered agreeable are deemed valid thus also covering the discomfort state of heat balance.

This contradiction can be mathematically presented in the following Fig.5. To develop the so-called static PMV Fanger took

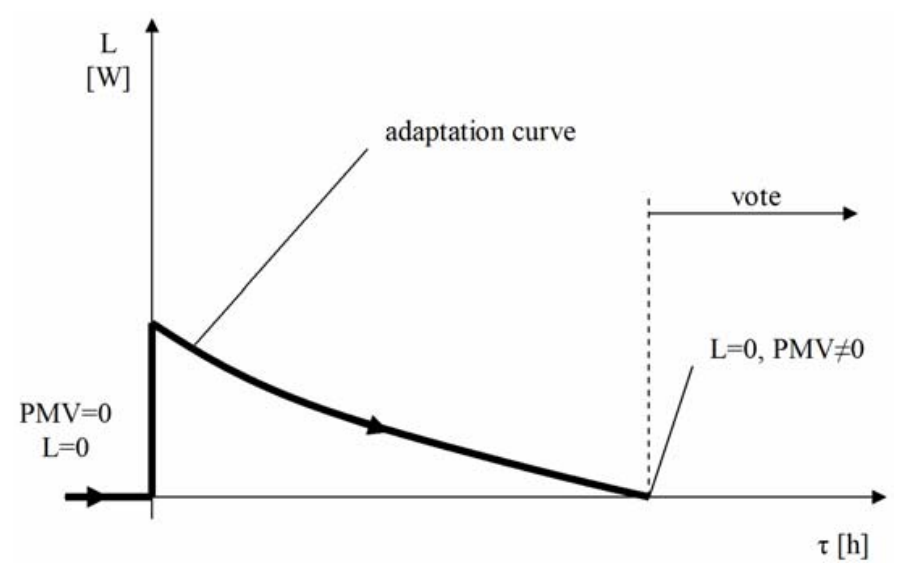

Fig. 5.

his starting point as the extrapolation of the dynamic energy balance of the human body and called a hypothetical condition static PMV. In a stochastic sense there exists a dynamic PMV that classified the ongoing changes of the actual thermal load 
$L$ of the human body in time and describes the changes of the human response in time as well as the response of the human body to the changes in the environment in time. This theory can grasp static conditions by recording the environmental parameters, eliminating changes in time and revealing the asymptotic conditions. To create such a simplified (and stochastically valid) theory we must start with the fact that the response of the human body to environmental changes can be described by the type of differential equation known from the regulation theory [3]:

$$
\begin{aligned}
A_{2} v^{\prime \prime}+A_{1} v^{\prime}+A_{0} v & =u \quad \text { or } \\
A_{1} v^{\prime}+A_{0} v & =u
\end{aligned}
$$

The variables are in theory vector variables but may be component variables as well. Variable components of $u$ are environmental impacts affecting humans i.e. $\mathrm{t}_{a}, \mathrm{t}_{m r t}, \mathrm{v}_{a i r}, \mathrm{p}_{a}$, while the components of $v$ variable are the physiological responses of humans i.e. $\mathrm{t}_{\text {core }}, \mathrm{t}_{\text {skin }}, \mathrm{t}_{s w}, \mathrm{Q}_{L}, \mathrm{Q}_{S W}, \mathrm{Q}_{D}, \mathrm{~S}, \mathrm{C}$, clothing, body mass, work intensity, other characteristics, constant parameters.

In a stochastic sense Eq. 27) can be written up for thermal load $L$ in humans and for the relationships of responses given to thermal load intensity.

If the functions in time of the physiological responses given to the unit jump function of the various environmental parameters were or are available we could define the so-called temporary functions of the human body. The solution of Eq. 27) for a unit jump input is shown graphically on Fig.6 If there are no jump

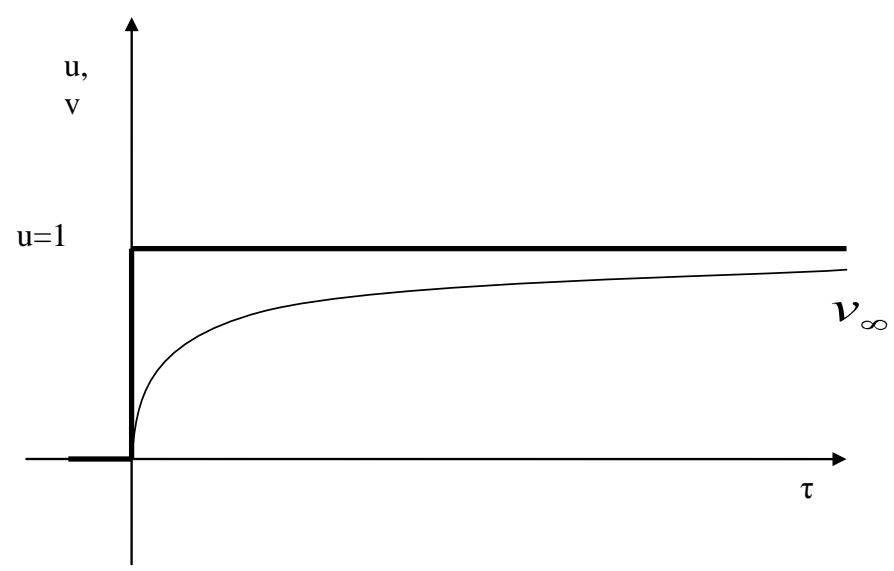

Fig. 6.

unit inputs and physiological responses given to them available in terms of environmental variable and impacts we can still define the temporary function for the physiological response of the human body in a stochastic sense, using Duhamel's principle.

Duhamel's principle describes the following: in the event the time function of a disturbance in the system is known then the time function for the system's response can be expressed by the convolution integral:

$$
v(t)=\int_{0}^{t} h^{\prime}(t-\tau) u(\tau) d \tau
$$

According to Eq. 28) if we knew the temporary function for a human physiological response to an environmental impact affecting a person then the time function for the examined physiological response can be determined for the time function of the examined environmental impact.

We can also do the inverse task: if we know the time function for a human physiological response to the time function of an environmental impact then using convolution integral 28) we can in theory determine the temporary function for the examined response. Our task is then to resolve an integral equation which is in fact far from being as difficult as it looks because by solving Eq. 27] the temporary function is

$$
h(t)=\frac{1}{A_{0}}\left(1-e^{-\frac{A_{0}}{A_{1}} t}\right)
$$

Eq. 29] is substituted into convolution integral equation (28). If value pairs $u v$ are available among the measurement results we can integrate Eq. 29) to get algebraic equations to determine $A_{0}$ and $A_{1}$ coefficients.

The above discussed examinations enable us to write up dynamic thermal sensation if thermal load $L$ is considered the input of equation 28) and the output is $\mathrm{Y}$ and PMV parameters.

We would like to draw your attention to the work carried out by Muhsin Kilic and Omer Kaynakli whose publication processed the actual adaptations of the human body in time with regard to the response functions of the human body to the various runnings of the different environmental impacts in time. These are presented below [4]. The diagrams graphically show the temporary functions of heat loss, TSENS (thermal sensation index), average skin temperature, average skin wettedness under the given environmental parameters (disturbances).

We must note that unlike Fanger the above mentioned authors used the term perceived temperature recommended by ASHRAE to describe PMV:

Based on the diagrams presented by the authors we defined for the temporary functions the $\mathrm{A}_{0}$ and $\mathrm{A}_{1}$ parameters of expression $h(t)=\frac{1}{A_{0}}\left(1-e^{-\frac{A_{0}}{A_{1}} t}\right)$ belonging to the $A_{1} v^{\prime}+A_{0} v=u$ differential equation (Table 3 and Table 4 .

\section{Conclusion}

In our research paper we analyzed the comfort equation describing the static and the so called static comfort equation of the human body's thermal balance. We presented the fundamentals of PMV, which is used to satisfy human comfort requirements optimally in premises serving for human residence and work. We described the sensitivity of PMV, produced by deriving PMV according to the influencing parameters. Based on the calculations of Muhsin Kilic and Omer Kaynakli, we conducted concrete calculations on our examples complied to define the temporary functions. It was possible only through the presentation of system theory. 
Tab. 3.

\begin{tabular}{|c|c|c|c|c|c|}
\hline & & & \multirow{2}{*}{\multicolumn{2}{|c|}{ Constants }} & \\
\hline & & \multirow[t]{3}{*}{ clo } & & & \multirow[t]{3}{*}{ Environment } \\
\hline & & & $\mathbf{A}_{0}$ & $A_{1}$ & \\
\hline & & & 0,14 & 1,43 & \\
\hline \multirow[t]{4}{*}{ Heat loss } & Sensible & 0,5 & 0,1 & 1,55 & \multirow{12}{*}{$\begin{array}{l}\mathrm{M}=80 \mathrm{~W} / \mathrm{m}^{2}, \\
\mathrm{R}=50 \%, \mathrm{~V}=0.1 \mathrm{~m} / \mathrm{s} \\
\mathrm{t}_{\mathrm{a}}=\mathrm{t}_{\mathrm{mrt}}=30^{\circ} \mathrm{C} \\
\\
\end{array}$} \\
\hline & & 1 & 0,1 & 1,64 & \\
\hline & Latent & 0,5 & 0,025 & 0,388 & \\
\hline & & 1 & 0,022 & 0,367 & \\
\hline \multirow{2}{*}{$\begin{array}{l}\text { Average skin } \\
\text { temperature }\end{array}$} & & 0,5 & 0,5 & 8,25 & \\
\hline & & 1 & 0,44 & 7,1 & \\
\hline \multirow{2}{*}{$\begin{array}{l}\text { Average skin } \\
\text { wettedness }\end{array}$} & & 0,5 & 2,67 & 45,3 & \\
\hline & & 1 & 2 & 37 & \\
\hline \multirow{4}{*}{$\begin{array}{l}\text { Thermal comfort } \\
\text { indices }\end{array}$} & \multirow[t]{2}{*}{ TSENS } & 0,5 & 0,4 & 5,8 & \\
\hline & & 1 & 0,36 & 4,54 & \\
\hline & \multirow[t]{2}{*}{ DISC } & 0,5 & 0,57 & 6,57 & \\
\hline & & 1 & 0,4 & 6,6 & \\
\hline \multirow[t]{4}{*}{ Heat loss } & \multirow[t]{2}{*}{ Forearm } & sensible & 0,08 & 1,04 & \multirow{12}{*}{$\begin{array}{l}\mathrm{M}=80 \mathrm{~W} / \mathrm{m}^{2}, \\
\mathrm{R}=50 \%, \mathrm{~V}=0.1 \mathrm{~m} / \mathrm{s} \\
\mathrm{t}_{\mathrm{a}}=\mathrm{t}_{\mathrm{mrt}}=30^{\circ} \mathrm{C}\end{array}$} \\
\hline & & \begin{tabular}{|l|} 
Iatent \\
\end{tabular} & 0,08 & 1 & \\
\hline & \multirow[t]{2}{*}{ Foot } & sensible & 0,025 & 0,45 & \\
\hline & & latent & 0,036 & 0,53 & \\
\hline \multirow[t]{4}{*}{ Skin temperature } & \multirow[t]{2}{*}{ Forearm } & 0,5 & 0,44 & 5,78 & \\
\hline & & 1 & 0,364 & 4,54 & \\
\hline & \multirow[t]{2}{*}{ Foot } & 0,5 & 0,3 & 3,33 & \\
\hline & & 1 & 0,3 & 3,5 & \\
\hline \multirow[t]{4}{*}{ Skin wettedness } & \multirow[t]{2}{*}{ Forearm } & 0,5 & 2,857 & 50 & \\
\hline & & 1 & 1,67 & 27,63 & \\
\hline & \multirow[t]{2}{*}{ Foot } & 0,5 & 1,11 & 12,78 & \\
\hline & & 1 & 1,11 & 10,56 & \\
\hline \multirow[t]{4}{*}{ Heat loss } & \multirow[t]{2}{*}{ Chest } & sensible & 0,087 & 2,83 & \multirow{4}{*}{$\begin{array}{l}\mathrm{M}=80 \mathrm{~W} / \mathrm{m}^{2}, \\
\mathrm{t}_{\mathrm{a}}=\mathrm{t}_{\mathrm{mrt}}=30^{\circ} \mathrm{C} \\
\mathrm{R}=50 \%, \mathrm{~V}=0.1 \mathrm{~m} / \mathrm{s} \\
\mathrm{Rcl}=0.5 \mathrm{clo}\end{array}$} \\
\hline & & latent & 0,025 & 0,475 & \\
\hline & \multirow[t]{2}{*}{ Pelvis } & sensible & 0,1 & 3,15 & \\
\hline & & latent & 0,027 & 0,51 & \\
\hline Skin temperature & Chest & 0,5 & 0,42 & 10,83 & $\mathrm{M}=80 \mathrm{~W} / \mathrm{m}^{2}$ \\
\hline & & 1 & 0,377 & 9,245 & $R=50 \%, V=0.1 \mathrm{~m} / \mathrm{s}$ \\
\hline & Pelvic & 0,5 & 0,42 & 10 & $\mathrm{t}_{\mathrm{a}}=\mathrm{t}_{\mathrm{mrt}}=30^{\circ} \mathrm{C}$ \\
\hline & & 1 & 0,377 & 8,33 & \\
\hline Skin wettedness & Chest & 0,5 & 2 & 35 & \\
\hline & & 1 & 1,18 & 19,41 & \\
\hline & Pelvic & 0,5 & 1,667 & 29,167 & \\
\hline & & 1 & 1,11 & 16,66 & \\
\hline
\end{tabular}

Tab. 4.

\begin{tabular}{|c|c|c|c|c|c|}
\hline & & \multirow[t]{2}{*}{$\mathrm{m} / \mathrm{s}$} & \multicolumn{2}{|c|}{ Constants } & \multirow[t]{2}{*}{ Environment } \\
\hline & & & $A_{0}$ & $A_{1}$ & \\
\hline \multirow[t]{4}{*}{ Heat loss } & Sensible & 0,05 & 0,1 & 1,5 & \multirow{12}{*}{$\begin{array}{l}\mathrm{M}=80 \mathrm{~W} / \mathrm{m}^{2}, \\
\mathrm{R}=50 \%, \mathrm{~V}=0.1 \mathrm{~m} / \mathrm{s}, \\
\mathrm{Rcl}=0.5 \mathrm{clo} \\
\mathrm{t}_{\mathrm{a}}=\mathrm{t}_{\mathrm{mrt}}=30^{\circ} \mathrm{C} \\
\\
\\
\\
\end{array}$} \\
\hline & & 0,3 & 0,08 & 1,76 & \\
\hline & Latent & 0,05 & 0,024 & 0,412 & \\
\hline & & 0,3 & 0,031 & 0,49 & \\
\hline \multirow{2}{*}{$\begin{array}{l}\text { Average skin } \\
\text { temperature }\end{array}$} & & 0,05 & 0,44 & 7,556 & \\
\hline & & 0,3 & 0,57 & 10,29 & \\
\hline \multirow{2}{*}{$\begin{array}{l}\text { Average skin } \\
\text { wettedness }\end{array}$} & & 0,05 & 1,82 & 32,72 & \\
\hline & & 0,3 & 5 & 80 & \\
\hline \multirow{4}{*}{$\begin{array}{l}\text { Thermal comfort } \\
\text { indices }\end{array}$} & \multirow[t]{2}{*}{ TSENS } & 0,05 & 0,36 & 4,54 & \\
\hline & & 0,3 & 0,5 & 6,75 & \\
\hline & \multirow[t]{2}{*}{ DISC } & 0,05 & 0,4 & 5,8 & \\
\hline & & 0,3 & 1 & 17,5 & \\
\hline \multirow[t]{4}{*}{ Heat loss } & Forearm & sensible & 0,067 & 0,9 & \multirow{12}{*}{$\begin{array}{l}\mathrm{M}=80 \mathrm{~W} / \mathrm{m}^{2}, \\
\mathrm{R}=50 \%, \mathrm{~V}=0.1 \mathrm{~m} / \mathrm{s}, \\
\mathrm{Rcl}=0.5 \mathrm{clo} \\
\mathrm{t}_{\mathrm{a}}=\mathrm{t}_{\mathrm{mrt}}=30^{\circ} \mathrm{C} \\
\\
\end{array}$} \\
\hline & & \begin{tabular}{|l|} 
latent \\
\end{tabular} & 0,033 & 0,567 & \\
\hline & Foot & sensible & 0,057 & 0,89 & \\
\hline & & \begin{tabular}{|l|} 
Iatent \\
\end{tabular} & 0,036 & 0,618 & \\
\hline \multirow[t]{4}{*}{ Skin temperature } & \multirow[t]{2}{*}{ Forearm } & 0,05 & 0,44 & 4,89 & \\
\hline & & 0,3 & 0,5 & 6,75 & \\
\hline & \multirow[t]{2}{*}{ Foot } & 0,05 & 0,25 & 3,125 & \\
\hline & & 0,3 & 0,29 & 3,714 & \\
\hline \multirow[t]{4}{*}{ Skin wettedness } & \multirow[t]{2}{*}{ Forearm } & 0,05 & 2 & 36 & \\
\hline & & 0,3 & 5 & 90 & \\
\hline & \multirow[t]{2}{*}{ Foot } & 0,05 & 1,11 & 8,33 & \\
\hline & & 0,3 & 1,11 & 13,89 & \\
\hline \multirow[t]{4}{*}{ Heat loss } & \multirow[t]{2}{*}{ Chest } & sensible & 0,087 & 2,74 & \multirow{12}{*}{$\begin{array}{l}\mathrm{M}=80 \mathrm{~W} / \mathrm{m}^{2}, \\
\mathrm{R}=50 \%, \mathrm{~V}=0.1 \mathrm{~m} / \mathrm{s}, \\
\mathrm{Rcl}=0.5 \mathrm{clo} \\
\mathrm{t}_{\mathrm{a}}=\mathrm{t}_{\mathrm{mrt}}=30^{\circ} \mathrm{C} \\
\\
\\
\\
\\
\end{array}$} \\
\hline & & \begin{tabular}{|l|} 
Iatent \\
\end{tabular} & 0,031 & 0,523 & \\
\hline & \multirow[t]{2}{*}{ Pelvis } & sensible & 0,095 & 3,14 & \\
\hline & & \begin{tabular}{|l|} 
Iatent \\
\end{tabular} & 0,031 & 0,554 & \\
\hline \multirow[t]{4}{*}{ Skin temperature } & \multirow[t]{2}{*}{ Chest } & $\begin{array}{l}0,05 \\
\end{array}$ & 0,44 & 11,33 & \\
\hline & & 0,3 & 0,44 & 12,44 & \\
\hline & \multirow[t]{2}{*}{ Pelvic } & 0,05 & 0,44 & 10,67 & \\
\hline & & 0,3 & 0,5 & 13,75 & \\
\hline \multirow[t]{4}{*}{ Skin wettedness } & Chest & 0,05 & 1,43 & 24,29 & \\
\hline & & 0,3 & 3,33 & 46,67 & \\
\hline & Pelvic & 0,05 & 1,25 & 20,625 & \\
\hline & & 0,3 & 2,5 & 40 & \\
\hline
\end{tabular}

Terms:

$H$

$\dot{Q}_{L}$

$\dot{Q}_{\text {re }}$

$\dot{Q}_{d}$

$\dot{Q}_{S W}$

$\dot{Q}_{K}$

$\dot{Q}_{S}$

$\dot{Q}_{C}$

Icl

$\mathrm{L}$

$\mathrm{M} / \mathrm{A}_{D u}$

$\mathrm{t}_{b}$

$\mathrm{t}_{c}$

$\mathrm{t}_{a}$

$\mathrm{t}_{m}$

$\mathrm{t}_{s}$

$\dot{q}_{k o n v}$

$\dot{q}_{s u g}$

$\mathrm{W}$

$\mathrm{t}_{l}$

$\mathrm{t}_{\text {mrt }}$

$\mathrm{v}_{\text {air }}$

$\mathrm{p}_{a}$

$\mathrm{Q}_{S W} / \mathrm{A}_{D u}$

$\mathrm{k}$

$\mathrm{T}$

r

W

$\mathrm{q}_{m}$

$\rho_{b l}$

$\mathrm{w}_{b l}$

$\mathrm{T}_{\text {artbl }}$

$c_{b l}$

$\mathrm{t}$

$\rho$ internal heat production in the human body dry respiration heat loss

latent respiration heat loss

heat loss by skin diffusion

heat loss by evaporation of sweat

heat transfer from the skin to the outer surface

heat loss by radiation

heat loss by convention

thermal resistance of clothing

thermal load

metabolic rate

mean skin temperature

surface temperature of clothing

ambient temperature

internal (core) temperature of the human body

surface temperature

heat loss by convention

heat loss by radiation

external mechanical work

air temperature

mean radiant temperature

relative air velocity

partial water vapour pressure

heat loss by skin diffusion and evaporation of sweat

tissue conductivity

tissue temperature

radius

geometry parameter

metabolism

density of the blood

blood perfusion rate

arterial blood temperature

heat capacity of blood

time

tissue density 


\section{References}

1 Fanger P O, Thermal Comfort, Analysis and Applications in Environmental Engineering, Danish technical press, Copenhagen, 1970.

2 Bánhidi L, Kajtár L, Komfortelmélet, Múegyetemi kiadó, Budapest, 2000.

3 Száday R, A szabályozáselmélet elemei, Múszaki könyvkiadó, Budapest, 1966.

4 Muhsin Kilic, Omer Kaynakli, Investigation of indoor thermal comfort under transient conditions, Science direct 40 (2005), 165-174.

5 Bánhidi L, Garbai L, Bartal I, Complex guide to human comfort, usefulness of static and dynamic PMV, Gépészet (May 29 2008).

6 Determination of the PMV and PPD indices and specification of the conditions for thermal comfort. ISO 7730 1994, ISO 7726, MSZ CR 1752.

7 Mihaela Baritz, Luciana Cristea, Diana Cotoros, Ion Balcu, Thermal human body behaviour analyze during cycling movements, WSEAS International Conference on Heat transfer, HTE '08 (Rhodes, Greece, August 20 2008).

8 ASHRAE handbook - fundamentals, Atlanta: American Society of Heating, Refrigeration and Air-Conditioning Engineers, 1989. chapter 8.

9 McCullough E A, Jones B W, Tamura T, A data base for determining the evaporative resistance of clothing, ASHRAE Transactions 95/2 (1989), 316-28.

10 Kaynakli O, Unver U, Kilic M, Evaluating thermal environments for sitting and standing posture, International Communications in Heat and Mass Transfer 30/8 (2003), 1179-88.

11 Bánhidi L, Garbai L, Bartal I, Research on static and dynamic heat balance of the human body, Wseas Transactions on Heat and Mass Transfer 3 (July 2008), 187-197.

12 De Dear RJ, Arens E, Hui Z, Ogura M, Convective and radiative heat transfer coefficients for individual human body segments, International Journal of Biometeorology 40 (1887), 141-56. 